\title{
Sistema de Semáforos Inteligentes (SSI) para Controle de Fluxo de Veículos Automotivos
}

\author{
Tiago Pereira e Golberi de Salvador Ferreira \\ Centro Federal de Educação Tecnológica de Santa Catarina
}

\begin{abstract}
Resumo- Buscando amenizar alguns problemas relacionados à má organização do trânsito, principalmente no que diz respeito ao controle de fluxo de veículos, este artigo apresenta um Sistema de Semáforos Inteligentes (SSI), utilizado para gerar melhores seqüências de tempo nos semáforos. Isto é feito com base em três aspectos fundamentais: sensoriamento das vias, comunicação entre os semáforos e programação lógica. Para validar os resultados, uma simulação computacional é realizada para testar a programação semafórica e os dispositivos de acionamento dos semáforos.
\end{abstract}

Palavras-chave- controle de tráfego, onda verde, semáforos inteligentes.

Abstract- In order to minimize some problems related to car traffic chaos, mainly those concerned to vehicles flux, this paper presents an Intelligent Semaphore System, used to generate better time sequences. The system is based on three main aspects: detection of vehicles, communication between semaphores, and logical programming. Aiming to validate the results, a computational simulation is accomplished to test the programming of the semaphores intelligence and the drivers devices. semaphores.

Key-words - traffic control, green wave, intelligent

\section{INTRODUÇÃO}

Uma das maiores causas de mortes no mundo está relacionada aos acidentes de trânsito. São diversos os fatores que levam a isso, especialmente no Brasil: acessos mal sinalizados, imprudência, excesso de velocidade, estresse dos motoristas, engarrafamentos, etc.

Atualmente, a maioria dos semáforos instalados no País possui pouca ou quase nenhuma inteligência, onde os tempos de abertura são fixos e predefinidos, tornando o sistema ineficiente em eventuais imprevistos como: intempéries, eventos sociais e esportivos de grande fluxo de pessoas, horários de pico, e outros.

Em busca de uma solução que amenize este problema o presente trabalho apresenta um Sistema de Semáforos Inteligentes (SSI), que objetiva propiciar maior fluidez no trânsito, economia de combustível, diminuição de estresse de motoristas e passageiros nos veículos, prevenção de possíveis acidentes relacionados aos semáforos, e tantos outros fatores desejáveis para um trânsito eficiente e seguro.

O sistema apresenta como diferencial a análise através de sensores de fluxo de veículos do trânsito em uma malha viária, para obter melhores seqüências de tempos de aberturas semafóricos. Para tanto, foi desenvolvido um sistema de comunicação, criando um canal de troca de informações entre os semáforos e cruzamentos, tornando possível a análise e modificação do fluxo de veículos de uma malha viária. O diagrama apresentado na Fig. 1 representa a maneira como os sistemas estão interligados.

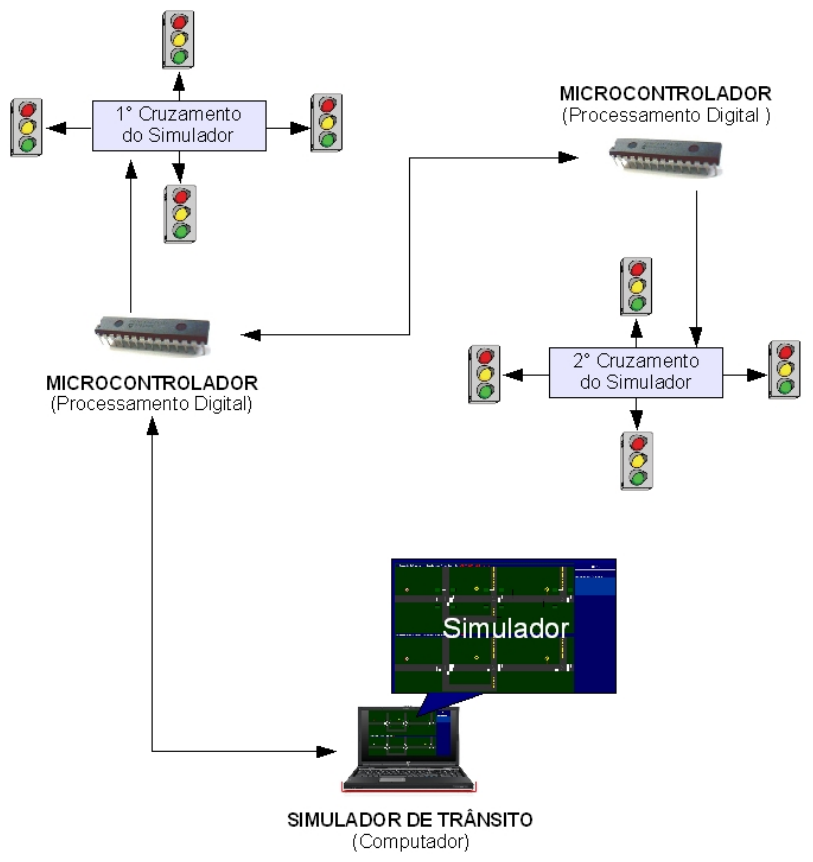

Fig. 1. Funcionamento do Sistema de Semáforos Inteligentes (SSI).

\section{SIMULADOR}

A implementação do protótipo em uma via pública real apresentaria custos elevados e diversos transtornos, pois haveria a necessidade de instalar sensores de laço magnético para detectar a passagem de veículos. Além disso, a possível necessidade de alteração da temporização dos semáforos originais da via durante a fase de testes e/ou modificações no protótipo poderia ocasionar dificuldades ou até mesmo incidentes. Diante disso, a alternativa encontrada foi o desenvolvimento de um software, que através de um computador convencional contendo o sistema operacional Windows XP, simulasse o trânsito em uma via, para testar a eficiência do sistema.

O simulador, cuja aparência é apresentada na Fig. 2, foi desenvolvido usando a linguagem de programação $\mathrm{C}++$ para atender aos seguintes requisitos: acesso aos periféricos do computador (Porta USB, etc.); interface e biblioteca gráfica e facilidade na utilização dos recursos gráficos [1]. 


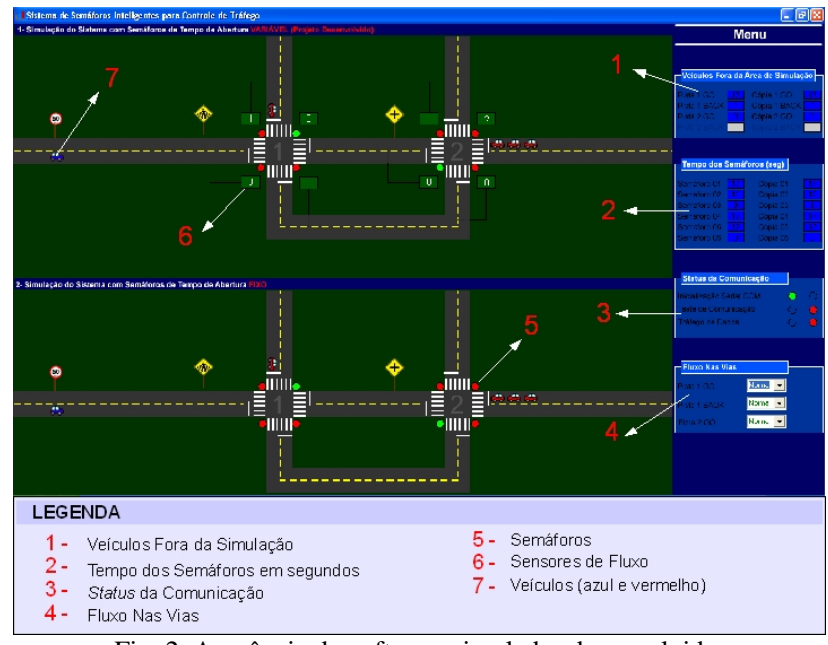

Fig. 2. Aparência do software simulador desenvolvido.

\section{HARDWARE}

O Hardware é composto de dois microcontroladores, um conversor Serial/USB e de outros componentes periféricos necessários ao funcionamento do sistema onde por definição, cada microcontrolador é considerado um cruzamento.

O seu principal objetivo é realizar o processamento no SSI, recebendo os valores dos sensores de laço da simulação, e aplicando a lógica de programação semafórica para montar uma resposta contendo os novos valores dos tempos de abertura semafóricos. Estes tempos são enviados de volta ao simulador, formando assim um sistema realimentado. De posse de novos valores, o simulador automaticamente atualiza os tempos dos semáforos criando uma "Onda Verde" de fluxo de veículos, que é a principal diferença entre um sistema comum e o SSI [2].

\section{COMUNICAÇÃO}

Caracterizada como etapa fundamental, a comunicação é responsável pela criação de um canal de troca de informações entre os módulos do sistema. Seu objetivo principal é garantir a integridade dos dados nessa troca de informações, reduzindo problemas causados por ruídos, além de ser responsável pelo sincronismo dos módulos e qualquer outro imprevisto relacionado à comunicação durante o funcionamento do sistema. A Fig. 3 mostra a topologia da rede desenvolvida.

Para estabelecer uma comunicação segura e eficiente entre os módulos do sistema, foi desenvolvido um protocolo exclusivo chamado de SemaBus, o qual foi projetado especialmente para dispositivos embarcados, mas especificamente para microcontroladores da família AVR da fabricante ATMEL [3]. O protocolo SemaBus funciona através da Requisição de dados, utilizando o princípio Master/Slave (Mestre/Escravo) no qual a requisição é feita exclusivamente pelo dispositivo configurado como Master, evitando assim colisões de dados, ou seja, dois dispositivos fazendo requisição e/ou enviando resposta ao mesmo tempo [4].

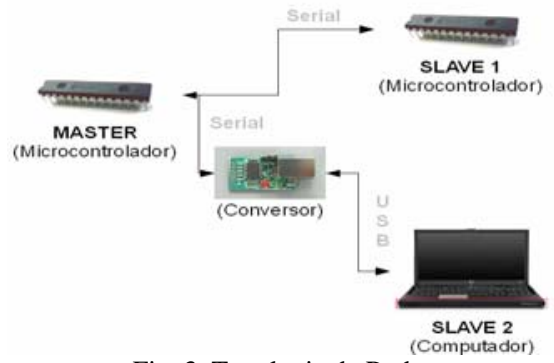

Fig. 3. Topologia da Rede.

\section{PROGRAMAÇÃo SEMAFÓRICA}

Do ponto de vista do cálculo dos tempos semafóricos é necessária à implementação de uma lógica coerente, que fundamente os valores aplicados. Entre as diversas lógicas existentes, utilizou-se neste projeto o método do Grau de Saturação. Este método foi escolhido por apresentar uma lógica de fácil aplicação, utilizada em diversos sistemas já existentes, como o Split Cycle and Offset Optimization Technique (SCOOT), sistema de controle semafórico em tempo real vastamente utilizado em âmbito mundial. [2] [4]

\section{ANÁlise DOS RESUltados}

O simulador de trânsito possui como recurso de análise de resultados a simulação simultânea do Sistema de Semáforos Convencional (tempo fixo) e o SSI proposto (tempo variável), conforme a Fig. 4. Através deste recurso podemos facilmente notar a redução do congestionamento de veículos no caso SSI (parte superior da Fig. 4). A maior diferença encontrada foi referente à Onda Verde, implantada no SSI, que resultou em um menor número de paradas, e consequentemente menor tempo de viagem por parte dos veículos do Sistema de Tempo Variável (parte inferior da Fig. 4).

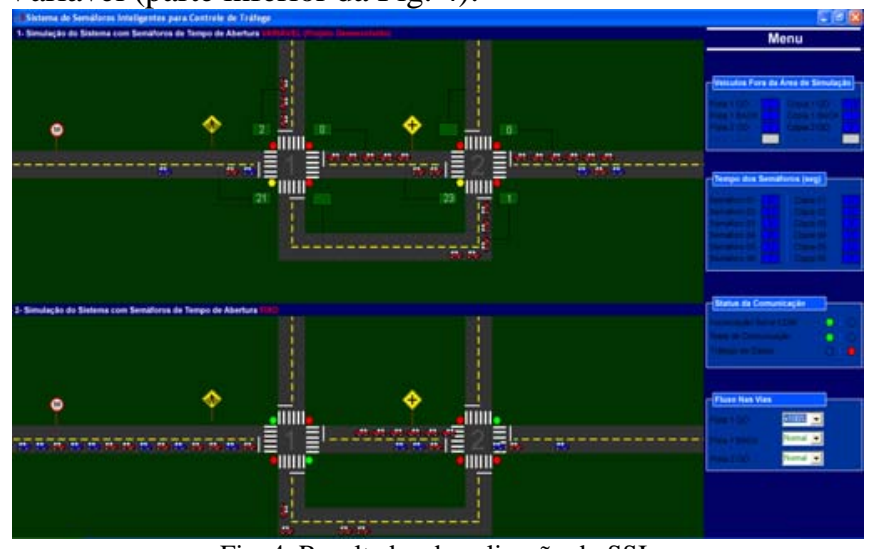

Fig. 4. Resultados da aplicação do SSI.

\section{REFERENCES}

[1] SCHILDT, Helbert. C++: The Complete Reference. 3. ed. New York: Osbourne, 1998.

[2] VILANOVA, Luiz Molist. Programação de um semáforo usando o método do grau de saturação. São Paulo, 2005. Disponível em: <http://www.sinaldetransito.com.br>. Acesso em: 2 outubro 2007.

[3] ATMEL. Datasheet ATMEGA8. Disponível em: <http://www.atmel.com>. Acesso em: 2 agosto 2007.

[4] PEREIRA, Tiago. Sistema de Semáforos Inteligentes para Controle do Fluxo de Veículos Automotivos. Monografia (Graduação em Sistemas Eletrônicos) - CEFET/SC, Florianópolis, 2007. Orientador: Golberi de Salvador Ferreira. 